ESTUDOS R:를

\title{
O Instituto Insikiran da Universidade Federal de Roraima: trajetória das políticas para a educação superior indígena
}

Marcos Antonio Braga de Freitas

\section{Resumo}

Apresenta a trajetória das políticas para a educação superior em atenção aos povos e comunidades indígenas de Roraima no âmbito da Universidade Federal de Roraima (UFRR), mostrando de que forma se dá o acesso e como se realizam as atividades didático-pedagógicas dos cursos de Licenciatura Intercultural e Gestão Territorial Indígena. Destaca ainda as parcerias, a manutenção dos cursos específicos, o acompanhamento dos estudantes indígenas nos demais cursos de graduação da Universidade e, também, os novos desafios para a implementação de cursos de pósgraduação lato sensu e strictu sensu, visando atender às demandas de indígenas egressos das graduações que almejam a continuidade da formação e da capacitação em nível de pós-graduação.

Palavras-chave: políticas públicas; educação escolar indígena; movimento indígena. 


\section{Abstract \\ The Roraima Federal University Insikiran Institute: indigenous higher education policies}

This article presents the Roraima Federal University higher education indigenous policies focusing on access and didactics concerning the indigenous population. Moreover, it highlights the partnerships, the maintanance of the specific formation courses and the monitoring of the indigenous students in other higher education courses at this University. Other aspects considered are the challenges to the post-graduate course implementation in other to offer to former indigenous students the possibility to continue their studies in a post-graduate level.

Keywords: public policies; indigenous education; indigenous movement.

\section{Contexto sociocultural indígena em Roraima}

No Estado de Roraima existem 32 terras indígenas em diferentes estágios de regularização fundiária, com uma extensão total de 3.250.256 hectares. Os maiores conflitos estão relacionados ao processo de desintrusão da terra indígena Raposa Serra do Sol, com uma extensão de 1.678.800 hectares e uma população em torno de 19.000 indígenas, onde existem várias fazendas (rizicultores) e algumas vilas habitadas por não índios. Cabe destacar aqui que o assunto se tornou conhecido nacionalmente em 2009, quando foi encaminhado a julgamento pelo Supremo Tribunal Federal (STF), para se analisar o mérito da constitucionalidade do processo demarcatório de reconhecimento histórico aos povos indígenas de Roraima.

A maior parte das terras indígenas já demarcadas está ainda invadida por posseiros que se utilizam da violência para manter a sua dominação.

Tabela 1 - Situação Fundiária de Terras Indígenas no Estado de Roraima

\begin{tabular}{|l|c|}
\hline \multicolumn{1}{|c|}{ Situação Fundiária } & $\mathbf{N}^{\mathbf{0}}$ de Terras Indígenas \\
\hline Demarcada e homologada & 1 \\
\hline Demarcadas, homologadas e registradas & 31 \\
\hline Total & $\mathbf{3 2}$ \\
\hline
\end{tabular}

Fonte: Funai, Coordenação Regional em Boa Vista (2011). 
Segundo o Setor de Saúde do Conselho Indígena de Roraima (CIR/Saúde, 2008), os povos indígenas localizados no leste de Roraima pertencem às etnias Macuxi (aproximadamente 25.400 pessoas), Wapichana (7.800 pessoas), Ingaricó (1.100 pessoas), Taurepang (720 pessoas), Patamona (100 pessoas) e Wai-Wai (680 pessoas). ${ }^{1}$

Para fins administrativos, esses povos estão distribuídos em nove regiões, sendo que em muitas aldeias coexistem famílias de etnias distintas. Vejamos na Tabela 2 o número de comunidades e o de pessoas, por região, referentes à população indígena no Estado de Roraima.

Tabela 2 - Distribuição das Comunidades Indígenas e Respectivas Populações, por Região - Roraima

\begin{tabular}{|l|c|c|}
\multicolumn{1}{|c|}{ Região } & Comunidades & População \\
\hline Serras & 98 & 9.570 \\
\hline Surumu & 25 & 2.721 \\
\hline Baixo Cotingo & 34 & 2.728 \\
\hline Raposa & 41 & 4.120 \\
\hline Amajari & 17 & 2.387 \\
\hline Taiano & 16 & 2.932 \\
\hline São Marcos & 33 & 4.398 \\
\hline Serra da Lua & 18 & 6.261 \\
\hline Wai Wai & 8 & 678 \\
\hline Total & 290 & 35.795 \\
\hline
\end{tabular}

Fonte: CIR/Saúde (2008); Funasa/MS (2009).

O povo Macuxi vive atualmente nas áreas de lavrado e de serras, na região do Rio Branco, e constitui a maior população indígena do Estado de Roraima, possuindo também várias aldeias na República Cooperativista da Guiana.

O povo Taurepang ocupa no Brasil uma pequena região no Alto Rio Surumu, na fronteira com a República Bolivariana da Venezuela, onde vive a maior parte de sua população.

Os povos Ingaricó e Patamona estão localizados no extremo norte do Estado, na região atravessada pelo rio Cotingo, sendo a maior parte de sua população residente na República Cooperativista da Guiana.

O povo Wapichana localiza-se na região sudeste do lavrado, possuindo também muitas aldeias na República Cooperativista da Guiana.

O povo Wai-Wai ocupa a região de florestas ao sul do Estado, em território que se localiza na interseção dos Estados de Roraima, do Pará e do Amazonas. Esse povo também possui comunidades na República Cooperativista da Guiana.

${ }^{1}$ Existe ainda em Roraima o povo Sapará, com um número aproximado de 28 pessoas, que hoje estão num processo de autoidentificação. Eles se localizam nas regiões do Taiano e Amajari, contudo ainda não aparecem quantificados em documentos oficiais.

Com relação à especificidade dos povos indígenas, é imprescindível saber que há uma diversidade étnico-cultural dessas populações em Roraima, que se apresenta por meio de diversas famílias linguísticas e línguas, e até mesmo de determinados grupos em outros Estados do Brasil, como Pará e Amazonas, e em países fronteiriços, como a República Bolivariana da Venezuela e a República Cooperativista da Guiana. 
O Quadro 1 destaca a realidade desses povos e suas respectivas populações.

Quadro 1 - Distribuição dos Povos Indígenas na Região Amazônica (Brasil e Países Limítrofes)

\begin{tabular}{|l|l|l|r|r|}
\hline \multicolumn{1}{|c|}{ Povo Indígena } & \multicolumn{1}{c|}{$\begin{array}{c}\text { Outras } \\
\text { Denominações } \\
\text { ou Grafias }\end{array}$} & $\begin{array}{c}\text { Família/ } \\
\text { Língua }\end{array}$ & População & Ano \\
\hline $\begin{array}{l}\text { Macuxi (Brasil e } \\
\text { Guiana) }\end{array}$ & $\begin{array}{l}\text { Makuxi, Macushi, } \\
\text { Pemon }\end{array}$ & Karíb & 25.400 & 2008 \\
\hline $\begin{array}{l}\text { Patamona (Brasil } \\
\text { e Guiana) }\end{array}$ & Kapon & Karíb & 100 & 2008 \\
\hline $\begin{array}{l}\text { Taurepang } \\
\text { Taulipang Pemon, }\end{array}$ & Karíb & 720 & 2008 \\
\hline Kaimiri-Atroari & Kinã, Kinja & Karíb & 230 & 2004 \\
\hline
\end{tabular}

Wai Wai

$\begin{array}{llll}\text { (Amazonas, } \quad \text { Waiwai, Wai-Wai } \quad \text { Kaŕb } & \text { 678 } & & \end{array}$

Roraima e Pará)

\begin{tabular}{|c|c|c|c|c|}
\hline $\begin{array}{l}\text { Ingaricó (Brasil, } \\
\text { Guiana e } \\
\text { Venezuela) }\end{array}$ & $\begin{array}{l}\text { Ingarikó Akawaio, } \\
\text { Kapon }\end{array}$ & Karíb & 1.100 & 2008 \\
\hline $\begin{array}{l}\text { Ye'kuana (Brasil e } \\
\text { Venezuela) }\end{array}$ & $\begin{array}{l}\text { Yekuana, Yekwana, } \\
\text { Maiongong }\end{array}$ & Karíb & 426 & 2000 \\
\hline $\begin{array}{l}\text { Wapichana } \\
\text { (Brasil e Guiana) }\end{array}$ & $\begin{array}{l}\text { Uapixana, } \\
\text { Vapidiana, } \\
\text { Wapixana, } \\
\text { Wapisiana, } \\
\text { Wapishana }\end{array}$ & Aruák & 7.800 & 2008 \\
\hline
\end{tabular}

Yanomami

(Roraima,

Amazonas $^{(2)} \mathrm{e}$

Venezuela -

Ianomâmi, Ianoama, Yanomami Yanomam

Xirianá

$10.771 \quad 2008$

Sanumá, Ninam)

\section{Total geral}

47.225

Fontes: Povos indígenas do Brasil (2000); Programa Waimiri Atroari (PWA, 2004); Serviço de Cooperação Yanomami (Secoya, 2001); CIR/Saúde (2008); Funai/Coordenação Regional em Boa Vista (2008).

Notas: ${ }^{(1)}$ Esse total refere-se às oito comunidades de Roraima.

(2) No Estado do Amazonas, segundo a Secoya (2001), há 1.297 Yanomami na região de Barcelos e Santa Isabel do Rio Negro.

Dessa forma, sendo a população de Roraima constituída por 450.479 pessoas (IBGE, 2010), o total da população indígena representa algo em torno de 13\% da população do Estado. Esse dado nos dá uma amostra da relevância da temática indígena para o contexto de Roraima, da Amazônia e do Brasil. 
A situação histórica vivida por esses povos indígenas em relação aos Impérios coloniais e depois com os Estados republicanos gerou um contexto de muita discriminação, preconceito e indiferença. Seus territórios foram sistematicamente invadidos, e as comunidades, encurraladas física e culturalmente. Essa situação não foi favorável ao reconhecimento da diversidade social e cultural, ou seja, do valor dos povos indígenas para a formação de Roraima e do Brasil.

O sistema educacional como um todo e a UFRR especificamente têm muito a contribuir para modificar esse estado de descaso e preconceito que ora impera. O Instituto Insikiran de Formação Superior Indígena cumpre, nesse contexto, um importante papel, não apenas por formar professores indígenas em nível superior e por dar apoio às atividades de educação promovidas pelas organizações e pelas escolas das comunidades, mas, sobretudo, por possibilitar a estada efetiva na universidade de uma população historicamente excluída. Acima de tudo, mais do que proporcionar o acesso de indígenas ao ensino superior, quase sempre pensado e projetado para as elites da população brasileira, as ações do Instituto têm o objetivo de tornar ostensiva a presença e a causa indígena no meio universitário e no cenário intelectual local e nacional.

O processo de formação de professores em si não esgota as demandas das comunidades indígenas que, ao conseguirem a formação de inúmeros alunos no ensino médio, pleiteiam então a continuidade dessa formação, agora em nível superior e nas mais diversas áreas de conhecimento. Desse modo é que as organizações indígenas têm, ao longo desses anos, se preocupado em responder a essa situação, resultando na criação do então Núcleo Insikiran.

As línguas indígenas de Roraima podem ser classificadas em três famílias linguísticas; no Quadro 2 estão listadas essas três famílias e suas respectivas línguas.

Quadro 2 - Línguas Indígenas em Roraima

\begin{tabular}{l|l}
\multicolumn{1}{c|}{ Famílias } & \multicolumn{1}{c}{ Línguas } \\
\hline Aruák & ${\text { Wapichana, Atoraiu }{ }^{(1)}}^{\text {Makuxi, Taurepang, Ingarikó, Y'ekuana, }}$ \\
\hline Karíb & Patamona, WaiWai, Waimiri Atroari \\
\hline Ianomâmi & Sanumá, Ianomamo, Ianomam, Ninam \\
\hline
\end{tabular}

Fonte: Melatti (2007).

Nota: ${ }^{(1)}$ Existe hoje apenas uma falante vivendo na comunidade Marupá, junto aos Wapichana, na região da Serra da Lua.

Além dessas informações sobre a diversidade étnico-cultural dos povos indígenas de Roraima, é importante destacar que alguns dados acerca da educação escolar indígena já foram levantados, como demonstra a Tabela 3, que informa sobre os números, por etapa de estudos, dos últimos seis anos nas escolas indígenas. 
Tabela 3 - Progressão do Número de Alunos Matriculados na Educação Indígena em Roraima

\begin{tabular}{|c|c|c|c|c|c|c|c|c|}
\hline \multirow{2}{*}{ Ano } & \multirow{2}{*}{$\begin{array}{l}\text { Educação } \\
\text { Infantil }\end{array}$} & \multicolumn{3}{|c|}{ Ensino Fundamental } & \multirow{2}{*}{$\begin{array}{l}\text { Ensino } \\
\text { Médio } \\
\text { De } 1^{\circ} \text { a } \\
3^{\circ} \text { Ano }\end{array}$} & \multirow{2}{*}{ EJA } & \multirow[b]{2}{*}{ Total } & \multirow{2}{*}{$\begin{array}{c}\text { Total de } \\
\text { Professores } \\
\text { em Exercício }\end{array}$} \\
\hline & & $\begin{array}{c}1^{\mathrm{a}} \text { a } 4^{\mathrm{a}} \\
\text { Série }\end{array}$ & $\begin{array}{c}5^{a} \text { a } 8^{a} \\
\text { Série }\end{array}$ & $9^{\circ}$ Ano & & & & \\
\hline 1999 & - & 4.950 & 1.311 & - & - & - & 6.261 & 471 \\
\hline 2000 & - & 4.867 & 1.383 & - & 154 & - & 6.404 & 426 \\
\hline 2001 & - & 4.902 & 1.816 & - & 628 & - & 7.346 & 565 \\
\hline 2002 & - & 4.386 & 2.004 & - & 222 & - & .6612 & 503 \\
\hline 2003 & - & 4.827 & 2.276 & - & 412 & - & 7.515 & 754 \\
\hline 2004 & - & 4.871 & 2.755 & - & 1.237 & - & 10.916 & - \\
\hline 2005 & 1.579 & 5.905 & 2.658 & - & 1.053 & 1.904 & 13.099 & - \\
\hline 2006 & 1.569 & 6.179 & 3.186 & 81 & 1.496 & 1.280 & 13.791 & - \\
\hline
\end{tabular}

Fonte: Censo Escolar MEC/Inep e Divisão de Educação Escolar Indígena da SECD-RR (2007).

Tabela 4 - Alunos Cursando o Ensino Médio Magistério por meio de Projetos

\begin{tabular}{lr} 
Alunos cursando o Projeto Tami'kan - Magistério Indígena/ & 300 \\
SECD-RR & 32 \\
$\begin{array}{l}\text { Alunos-professores Yanomami cursando formação Magistério } \\
\text { - Projeto Yarapiari/CCPY }\end{array}$ & 332 \\
\hline Total & 32
\end{tabular}

Fonte: CCPY e DEEI-SECD-RR (2008).

Nesse contexto, atendendo à demanda por implementação de políticas públicas de educação escolar indígena em Roraima, é criado em 2001, dentro da UFRR, o Núcleo Insikiran. Assim, a Licenciatura Intercultural torna-se uma referência para receber os egressos do magistério indígena (nível médio) e todos os que estão atuando nas escolas indígenas no sentido de dar continuidade aos seus estudos.

Os alunos egressos do ensino médio têm a opção de cursar outras graduações, como Administração, Biologia, Computação, Contabilidade, etc., visando atender às demandas específicas das organizações e comunidades indígenas. Mas estão sendo criados cursos específicos para fazer a gestão das terras indígenas no que tange ao gerenciamento, ao planejamento e à elaboração de projetos de autossustentação para as comunidades - por exemplo, o curso de "Gestão Territorial Indígena", que foi criado em 2009, com o ingresso de 120 indígenas ao longo desses três anos - e o curso na área de Saúde Coletiva, com ênfase em Gestão da Saúde Indígena, criado em 2011 e com previsão de ingresso de 40 alunos em 2012, para atender às demandas dos Distritos Sanitários Especiais Indígenas (Leste de Roraima e Yanomami e Ye'kuana), além dos egressos do ensino médio em expansão nas comunidades.

Portanto, o projeto da Licenciatura Intercultural surge a partir das reivindicações dos professores indígenas de Roraima para atender as suas demandas e necessidades educacionais, contando hoje com 237 alunos regularmente matriculados. 


\section{Breve histórico da criação do Instituto Insikiran}

A UFRR é a primeira instituição federal de ensino superior a implantar um curso específico de graduação para a formação de indígenas. Em 2001, a Universidade cria o Núcleo Insikiran, hoje transformado em Instituto Insikiran, conforme Resolução nº 009/2009-CUni, com o objetivo de desenvolver e articular com lideranças, professores, comunidades e organizações indígenas de Roraima e a sociedade em geral a formação profissional dos indígenas, de modo específico, diferenciado e intercultural.

Cabe destacar que o nome Insikiran é originário da mitologia dos povos indígenas que habitam o Monte Roraima, sendo para os índios Macuxi um dos filhos guerreiros de Makunaimî, irmão de Anikê, integrando toda a cosmologia de criação dos indígenas dessa região, segundo a tradição e cultura desses índios.

A criação do Núcleo veio atender a uma das demandas dos povos e das comunidades indígenas de Roraima que reivindicaram o acesso ao ensino superior por meio da Carta de Canauanim, ${ }^{2}$ elaborada em 2001 na Assembleia Geral dos Professores Indígenas de Roraima, e a UFRR respondeu ao compromisso social da instituição.

A ação política do movimento indígena de Roraima foi de suma importância para a criação do Insikiran enquanto resposta política e social da administração superior da UFRR em atender as reivindicações dos indígenas de Roraima. Nesse processo, pode-se destacar o papel da Organização dos Professores Indígenas de Roraima (Opirr, 2001) com trechos da Carta de Canauanim, ao afirmar:

Para fazer frente ao violento processo de colonização que impôs a nós fronteiras de dominação física, social e cultural, as lideranças e comunidades indígenas levantaram diversas problemáticas e se organizaram, buscando alternativas que permitissem melhorias nas condições de vida.

\section{$[\ldots]$}

Neste processo, em especial com relação à realidade educacional, no ano de 1985 realizou-se uma grande discussão "QUE ESCOLA TEMOS, QUE ESCOLA QUEREMOS". Uma das principais conclusões foi que o Governo do Estado (Roraima) deveria se preocupar com as problemáticas vividas nas comunidades (indígenas). Como um dos resultados desta discussão foi criado o Núcleo de Educação Indígena (NEI) na Secretaria Estadual de Educação, coordenado no início por não índios, mas que foi logo assumido por uma liderança indígena.

${ }^{2}$ Canauanim é uma comunidade indígena localizada no município de Cantá, Estado de Roraima Esse local sediou a assembleia geral dos professores indígenas do referido Estado.

É importante ressaltar que o Instituto Insikiran atua com o modelo de gestão compartilhada, tendo o Conselho do Instituto como espaço para discussões e deliberações das questões políticas e administrativas, sendo composto por: Direção da Unidade Acadêmica, Coordenações (gestão administrativa, extensão, pós-graduação e de cursos de graduação), representante dos professores formadores e discentes de cada curso, representante do corpo técnico-administrativo, Fundação Nacional do 
Índio (Funai), Divisão de Educação Indígena da Secretaria de Estado da Educação, Cultura e Desportos (SECD-RR), Conselho Indígena de Roraima (CIR), Organização dos Professores Indígenas de Roraima (Opirr), Associação dos Povos Indígenas de Roraima (Apirr) e Organização das Mulheres Indígenas de Roraima (Omir), totalizando 17 membros.

Além do curso de Licenciatura Intercultural, o Instituto desenvolve atividades de pesquisa e extensão fomentadas pelos projetos e programas que vêm sendo construídos com o apoio de parcerias, como a da Rede Internacional de Estudos Interculturais (Ridei) com a Pontifícia Universidade Católica do Peru (PUC-Peru), nos anos de 2006-2008, e a do Programa E'ma Pia de Acesso e Permanência de Indígenas no Ensino Superior com a Fundação Ford e o Laboratório de Pesquisas em Etnicidade, Cultura e Desenvolvimento (Laced) do Museu Nacional da Universidade Federal do Rio de Janeiro (UFRJ), como parte do Projeto Trilhas de Conhecimentos, nos anos de 2005-2007, além do Prodocência/Pibid e Observatório de Educação Escolar Indígena com financiamento da Capes/MEC, que vem atuando em determinadas escolas indígenas com a questão de políticas linguísticas, projetos político-pedagógicos e materiais didáticos.

O Programa E'ma Pia contribuiu para essa discussão nas unidades acadêmicas da Universidade juntamente com a Pró-Reitoria de Ensino e Graduação (Proeg), com a ampliação de vagas nos demais cursos de graduação da instituição para atender outras demandas das comunidades e povos indígenas de Roraima que reivindicavam acesso aos cursos de Medicina, Direito, Engenharia, Agronomia, Administração, entre outros, originando, assim, o Processo Seletivo Específico para Indígenas (Psei).

É importante destacar que os povos indígenas que estão nos cursos do Instituto Insikiran pertencem aos Macuxi (maioria), Wapichana, Ingaricó, Wai Wai, Taurepang, Ye’kuana, Patamona, Sapará e Yanomami.

\section{Curso de Licenciatura Intercultural}

Em 2002 foi aprovado o Projeto Político-Pedagógico (PPP) da Licenciatura Intercultural, que tem como princípios norteadores da proposta pedagógica a transdisciplinaridade, a interculturalidade e a dialogia social. O curso abrange três áreas de habilitação: Comunicação e Artes, Ciências da Natureza e Ciências Sociais. A ferramenta na construção de trilhas teórico-metodológicas na formação do professor indígena se dá por meio da pesquisa-ação (UFRR. Cepe, 2008).

Entre os princípios norteadores do PPP, vale destacar a concepção de interculturalidade, que, nas propostas curriculares, é um dos desafios nas discussões dos saberes indígenas com os ditos conhecimentos técnico-científicos institucionalizados no meio acadêmico. Nesse aspecto, os saberes indígenas são trabalhados durante os temas contextuais num debate com a polifonia indígena, e, além desses momentos, lideranças indígenas são convidadas de forma pontual para colaborar nos referidos temas. 
Para corroborar esse conceito em discussão, eis uma citação de Celia Collet (2006, p. 123):

[...] a educação intercultural seria vista como instrumento de inclusão das minorias e de atribuição de poder às populações que estão às margens da cultura dominante. A idéia subjacente a essa visão seria que, através do domínio tanto de seus códigos específicos como dos códigos "ocidentais" ou nacionais, as minorias poderiam reivindicar um espaço na sociedade e na economia nacionais e globais.

Nesse aspecto, os movimentos indígenas de Roraima, mostrando sua polifonia nos processos de afirmação identitária e autonomia, reivindicam e lutam por um espaço político no âmbito da UFRR para garantir suas demandas educacionais e sociais. Portanto, a proposta pedagógica do Curso de Licenciatura Intercultural tem esse constante desafio de participação, colaboração e discussão do conceito em tela a partir dos etnoconhecimentos presentes no universo indígena.

Outro princípio do nosso projeto pedagógico trata do enfoque da transdisciplinaridade que vem na perspectiva de romper com as tradicionais disciplinas dos currículos na maioria dos cursos de graduação na educação superior. Na tentativa de ruptura desse modelo tradicional na pedagogia do ensino brasileiro é que o PPP da Licenciatura Intercultural destaca a importância desse princípio na formação do professor indígena. Aqui ressalto a afirmação de Basarab Nicolescu (2000, p. 11):

A interdisciplinaridade tem uma ambição daquela da pluridisciplinaridade. Ela diz respeito à transferência de métodos de uma disciplina para outra. [...] A transdisciplinaridade, como o prefixo "trans" indica, diz respeito àquilo que está ao mesmo tempo entre as disciplinas, através das disciplinas e além de qualquer disciplina. Seu objetivo é a compreensão do modo presente, para o qual um dos imperativos é a unidade do conhecimento.

Ao trabalhar com temas contextuais na formação do professor estamos reforçando a ideia de uma visão holística dos saberes indígenas em interação com as demais formas de conhecimento, caminhando para esse diálogo intercultural e exercício da transdisplinaridade como pressuposto da prática docente. Não só Nicolescu corrobora essa reflexão, mas também o pensamento complexo de Edgar Morin (2005, p. 17), quando afirma:

A missão transecular faz com que a Universidade conclame a sociedade a adotar sua mensagem e suas normas: ela introduz na sociedade uma cultura que não é feita para sustentar as formas tradicionais ou efêmeras do aqui e agora, mas que está pronta para ajudar os cidadãos a rever seu destino hic et nunc. A Universidade defende, ilustra e promove no mundo social e político valores intrínsecos à cultura universitária, tais como autonomia da consciência e a problematização, cujas consequências expressam-se no fato de que a investigação deve manter-se aberta e plural, que a verdade tenha sempre primazia sobre a utilidade, que a ética do conhecimento seja mantida.

A formação intercultural trabalha essa problematização do conhecimento, tendo a ferramenta da metodologia pela pesquisa como 
instrumental para esse exercício da vivência transdisciplinar e o olhar da interculturalidade e a dialogia social como princípios teórico-metodológicos.

As aulas da primeira turma tiveram inicio em julho de 2003. A etapa de estudos presenciais intensivos ocorre no campus do Paricarana da UFRR, em Boa Vista, nos meses de janeiro e fevereiro e julho e agosto, no momento em que os professores indígenas estão de recesso nas escolas. Além desse momento presencial, a proposta pedagógica do curso contempla também os encontros pedagógicos como parte integrante na formação do cursista, quando os professores formadores do Instituto Insikiran se deslocam a determinadas regiões para realizarem o acompanhamento didático-pedagógico do cursista, visando aprofundar conhecimentos e discutir o andamento dos trabalhos que os cursistas desenvolvem nas comunidades como parte do aprimoramento do processo de construção dos conhecimentos.

Outro aspecto que merece destaque é o do professor formador, que é selecionado a partir de sua trajetória profissional em relação a sua experiência com povos indígenas. Por isso, no concurso público, o candidato deve apresentar um memorial que demonstre essa trajetória, uma proposta de trabalho que evidencie a sua atuação profissional no curso e o próprio currículo, em que mostre o percurso de vivência e prática com indígenas, seja na formação, seja na pesquisa científica ou profissional.

A capacitação do professor formador ocorre no próprio curso: na prática em sala de aula, nos encontros pedagógicos e quando a unidade promove oficinas de capacitação entre os docentes; por ser uma equipe multidisciplinar e profissional com história de vida e trajetórias profissionais diferentes, esse aperfeiçoamento é importante para consolidar um PPP que se propõe romper com a pedagógica tradicional e caminhar numa perspectiva problematizadora também com o aporte teórico de Paulo Freire.

Em novembro de 2003, foi firmado o convênio entre a Secretaria de Estado da Educação, Cultura e Desportos (SECD-RR) e a UFRR, tendo a Fundação Ajuri de Apoio ao Desenvolvimento da UFRR como executora dos recursos financeiros, visando qualificar 60 professores indígenas que atuam na educação básica do sistema estadual de ensino, por meio do curso de Licenciatura Intercultural.

Em 2005, ingressaram mais 120 professores indígenas via concurso vestibular específico, sendo 60 no primeiro semestre e 60 no segundo. Até então, o curso de Licenciatura Intercultural foi mantido com esse recurso e o da própria instituição, com a infraestrutura e a contratação de professores efetivos. Nesse mesmo ano, a UFRR concorreu ao edital do Programa de Apoio às Licenciaturas Indígenas (Prolind-MEC) para manutenção das licenciaturas indígenas, quando o projeto do curso foi contemplado. No segundo semestre do ano de 2007, ingressaram mais 60 professores indígenas (turmas G e H), em 2009, entraram mais 60 (turmas I e J) e em 2010, mais 60 (turmas K e L), totalizando 360 professores cursistas, tendo o apoio financeiro para manutenção do curso por meio da Secad/Sesu/MEC, todos atendidos pelo Programa Prolind. 
Além desses, citam-se o Prodocência/Pibid e o Observatório da Educação Escolar Indígena, com financiamento da Capes/MEC.

Desse total, formaram-se 118 professores indígenas com graduação em Licenciatura Intercultural nas três áreas de habilitação - Comunicação e Artes, Ciências da Natureza e Ciências Sociais -, sendo 37 graduados em 28 de março de 2009 e 81 em 9 de abril de 2010. Cabe destacar que, ao longo do período de 2003 a 2010, houve dois óbitos e quatro desistentes.

Com o intuito de dar continuidade à oferta de vagas para a qualificação de professores indígenas no Estado de Roraima, novas demandas surgem nesse processo de implementação da educação escolar indígena, ora não contemplado nos atuais convênios e parcerias.

Há atualmente 237 alunos regularmente matriculados no curso de Licenciatura Intercultural, com a previsão de ingresso de 60 alunos por ano, chegando a atingir 420 professores nos próximos cinco anos, totalizando 540 professores indígenas ao longo de dez anos.

Nesse sentido, o governo de Estado de Roraima, por meio da SECD-RR, tem o importante papel de responder às demandas advindas das comunidades indígenas, uma vez que os professores que atuam no sistema estadual de ensino estão sendo qualificados ao cursarem a Licenciatura Intercultural - e, assim, têm melhorado a sua prática pedagógica nas escolas indígenas.

Destacamos que foi pactuado em reunião do dia 27/08/2008 o atendimento às novas demandas dos alunos do curso de Licenciatura Intercultural - por intermédio do então secretário Luciano Moreira (in memoriam), do Insikiran da UFRR e do Centro Acadêmico da Licenciatura Intercultural - para a manutenção das turmas, mediante a autorização de um aditivo ao convênio de 2003, no valor de $\mathrm{R} \$ 108$ mil reais, para a concessão de bolsa no valor individual de R\$ 600,00, beneficiando 180 alunos.

\section{Curso de bacharelado em Gestão Territorial Indígena}

O Projeto Político Pedagógico (PPP) do curso de Bacharelado em Gestão Territorial Indígena foi aprovado pelo Conselho de Ensino, Pesquisa e Extensão (Cepe), conforme a Resolução no 12/09, de 7 de agosto de 2009 , e o curso foi criado pelo Conselho Universitário (CUni), de acordo com a Resolução nº 011/2009, de 13 de agosto de 2009.

Esse curso veio atender às demandas de formação de gestores indígenas para o etnodesenvolvimento dos territórios, sendo contemplado dentro da política do Programa de Reestruturação das Universidades Federais (Reuni-MEC). Ele teve início em março de 2010, com aulas presenciais nos meses de março e abril, no campus do Paricarana, em Boa Vista, Estado de Roraima, o que no projeto político pedagógico é denominado de tempo-escola. Após esse período, os alunos retornam às organizações de base para o tempo-comunidade, onde se inicia o diagnóstico social e ambiental das etnorregiões políticas dos povos indígenas 
de Roraima. Em 2010 ingressaram mais 40 alunos no curso de Gestão Territorial Indígena e 40 em 2011, totalizando 120 alunos regularmente matriculados.

Segundo o PPP do curso, o objetivo geral é formar e habilitar gestores indígenas para atuarem profissionalmente em atividades que envolvam a gestão de territórios indígenas no âmbito da Região Amazônica, particularmente formulação, desenvolvimento, monitoramento e avaliação de políticas, projetos e ações que garantam a autossustentação, a defesa de seu patrimônio cultural e natural e a gestão da infraestrutura e dos empreendimentos necessários para viabilizarem a qualidade de vida de sua população.

A proposta político-pedagógica do curso abrange quatro ênfases em sua estrutura curricular: atividades produtivas e manejo ambiental; patrimônio indígena; serviços e infraestrutura; e empreendimentos sociais.

O campo de atuação do egresso do curso, ou seja, do profissional formado em Gestão Territorial Indígena, poderá ser: comunidade indígena ou organizações civis e setor governamental, nas esferas municipal, estadual ou federal. Além desse aspecto, o referido curso destaca que as competências gerais do gestor indígena são administrativa, científica, política, sociocultural e técnica.

Para a implementação do referido curso foram contratados sete professores, nas áreas de Geografia Humana, Ciências Sociais, Ecologia de Sistemas Amazônicos, Gestão de Projetos, Etnodesenvolvimento e Direito Ambiental e Agrário - todos "brancos".

\section{Acesso pelo vestibular específico}

1) Ingresso no curso de Licenciatura Intercultural:

$1^{\text {a }}$ fase - eliminatória e classificatória: prova de redação, que pode ser escrita em língua portuguesa ou em língua indígena. Para a tradução das redações nas línguas indígenas são contratados serviços de indígenas falantes para colaborar nas traduções e correções dessas avaliações;

$2^{a}$ fase - eliminatória e classificatória: entrevista realizada por uma banca examinadora composta por três avaliadores com experiência em educação indígena, lotados no Instituto Insikiran, e por colaboradores;

$3^{a}$ fase - classificatória: prova de títulos e análise curricular.

2) Ingresso no curso de Gestão Territorial Indígena:

$1^{\text {a }}$ fase - eliminatória: prova de redação e prova objetiva;

$2^{\mathrm{a}}$ fase - classificatória: análise do currículo e memorial.

3) Ingresso por meio de vagas extras (demais cursos de graduação da UFRR):

$1^{\text {a }}$ fase - prova de redação; 
$2^{\mathrm{a}}$ fase - na primeira experiência, em 2007, houve a entrevista com uma banca examinadora, substituída pela aplicação de um questionário a partir de 2008. Em 2009 foram aplicadas questões dissertativas por áreas de conhecimentos, em vez do questionário;

$3^{\text {a }}$ fase - teste de habilidade específica, exclusivo para o curso de Medicina.

Em todo esse processo de elaborar os editais, visando publicar, operacionalizar e executar processos específicos e diferenciados, a Comissão Permanente de Vestibular (CPV) da UFRR tem mostrado flexibilidade e abertura de diálogo para um melhor entendimento de políticas específicas em atenção aos povos indígenas. Hoje se realiza o vestibular unificado, em que são ofertadas vagas nos cursos de Licenciatura Intercultural, Gestão Territorial Indígena e vagas extras nos demais cursos da instituição.

Após o acesso, o maior desafio é garantir a permanência desses indígenas nos cursos. Há problemas no que se refere à questão econômica (por exemplo, despesas com manutenção do cursista na cidade), ao aspecto didático-pedagógico e à superação do preconceito e da discriminação que ainda permeiam a comunidade acadêmica de um modo geral.

Outro aspecto que deve ser levado em consideração no item referente à permanência é a reformulação das estruturas curriculares com o objetivo de envolver os saberes indígenas nos processos de construção de novos conhecimentos - a possibilidade do chamado "diálogo intercultural", ou seja, a interculturalidade como princípio no processo de ensino e aprendizagem.

Nesse sentido, há vários desafios para fortalecer a política de acesso e permanência de indígenas na educação superior, como:

- acompanhamento pedagógico dos cursos que estão ofertando vagas extras;

- a garantia de bolsas pela UFRR visando à permanência, para aquisição de materiais didáticos, deslocamento, hospedagem e alimentação;

- a criação de um grupo de trabalho para avaliação e monitoramento dessa política no sentido de instrumentalizar a administração superior para aprimorar o processo seletivo específico para indígenas com o intuito de ampliar as políticas de ações afirmativas;

- a realização periódica de reuniões com alunos e professores orientadores;

- a criação do professor orientador em cada curso, para acompanhar o desempenho dos alunos e ser a interlocução entre a Pró-Reitoria de Ensino e Graduação (Proeg), o Instituto Insikiran e a unidade acadêmica que conta com a presença de indígenas.

Sendo assim, é importante fortalecer o debate de ações afirmativas no âmbito da UFRR por meio de seminários e palestras sobre temas como "Interculturalidade", "Diálogos de Saberes Indígenas, Conhecimentos 
Tradicionais e Técnico-Científicos", destacando o ganho social e político do acesso de indígenas aos cursos de graduação da Instituição.

\section{Expansão do número de vagas na educação superior indígena no âmbito da UFRR}

A implantação de políticas específicas para garantir o acesso de indígenas ao ensino superior tem mostrado a expansão de vagas nos cursos de graduação da UFRR, seja em cursos específicos, seja nos demais cursos da instituição, mediante a criação de vagas extras. A Tabela 5 configura esse crescimento.

Tabela 5 - Expansão de Vagas Específicas para Indígenas no Âmbito da UFRR

\begin{tabular}{|c|c|c|c|c|c|}
\hline Anos & Extras $^{(1)}$ & $\begin{array}{c}\text { Licenciatura } \\
\text { Intercultural }\end{array}$ & $\begin{array}{c}\text { Gestão Territorial } \\
\text { Indígena }\end{array}$ & Saúde & Total \\
\hline 2003 & - & 60 & - & - & 60 \\
\hline 2005 & - & 120 & - & - & 120 \\
\hline 2007 & 11 & 60 & - & - & 71 \\
\hline 2008 & 23 & - & - & - & 23 \\
\hline 2009 & 34 & 60 & - & - & 94 \\
\hline 2010 & 41 & 60 & 80 & - & 181 \\
\hline 2011 & 57 & 60 & 40 & - & 157 \\
\hline
\end{tabular}

Fonte: Universidade Federal de Roraima (UFRR), Comissão Permanente de Vestibular, Instituto Isikiran (2011).

Nota: ${ }^{(1)}$ Vagas nos demais cursos de graduação da UFRR, específicas para indígenas.

A Tabela 5 mostra os avanços de políticas específicas para indígenas no âmbito da UFRR, podendo-se afirmar que, hoje, o seu contingente é de aproximadamente $10 \%$ da população cursando o ensino superior. Essas políticas não se restringem ao acesso, mas também garantem as demandas dessa população para qualificação a partir de sua realidade, como saúde, por conta dos distritos sanitários, educação, em virtude da expansão da educação básica nas comunidades indígenas, e gestão territorial, para garantir a sustentabilidade das terras indígenas.

Portanto, esses três cursos vêm ao encontro das demandas prioritárias dos indígenas, além, é claro, de outras necessidades, como profissionais nas áreas de medicina, jornalismo, direito, agronomia, biologia, entre outras, atendidas pelas vagas extras.

\section{Novos desafios para a educação superior indígena na UFRR}

O Instituto Insikiran da UFRR passou por várias fases: i) o momento de criação e implementação da proposta política, pedagógica e institucional; 
ii) a etapa de consolidação, que veio com a contratação de professores para atuarem na Licenciatura Intercultural, e construção da sede própria, em 2006, totalizando $250 \mathrm{~m}^{2}$; iii) e a de expansão, em que foi construído o bloco de oito salas de aulas e concluído o bloco I, com cinco salas para professores, totalizando $600 \mathrm{~m}^{2}$, com recursos financeiros do Programa Reuni/MEC, além da criação do terceiro curso específico na área de gestão da saúde indígena em nível de bacharelado, com previsão de início das aulas em janeiro de 2012.

As demandas por novos cursos de graduação vêm atender aos desafios das comunidades e dos povos indígenas de Roraima na área de gestão territorial e ambiental das terras indígenas, no manejo dos recursos naturais existentes e outros que compõem a realidade do Estado. Além desse curso, dentro do processo de expansão do Instituto Insikiran, está previsto para 2012 um curso na área de saúde visando qualificar indígenas nessa área para atuarem nas comunidades, tendo em vista que, no contexto da distritalização da saúde indígena, o Estado de Roraima dispõe de dois Distritos Sanitários Especiais Indígenas (Leste de Roraima e Yanomami e Ye'kuana). Assim como os demais cursos, este deverá valorizar os saberes indígenas em seu currículo.

Outro aspecto importante nessa expansão é a demanda por cursos de pós-graduação já previstos no plano de metas do Insikiran, que tem a pretensão de implantar uma Especialização em Educação Escolar Indígena em 2012 e um Mestrado em Educação Intercultural em 2013, buscando dar continuidade aos estudos na formação de professores indígenas.

\section{Considerações finais}

O Instituto Insikiran da UFRR vem implementando políticas de acesso à educação superior aos povos indígenas de Roraima e consolidando políticas públicas de ensino superior a essas populações, respeitando as especificidades de cada povo e/ou comunidade e a diversidade étnico-cultural.

Nesse processo, é importante destacar também o diálogo permanente com as organizações de base e a participação nas assembleias como forma de controle social e legitimação de uma política construída e discutida coletivamente com o protagonismo indígena.

Além dos cursos específicos para indígenas ofertados pelo Instituto Insikiran, há vagas extras nos demais cursos da UFRR no âmbito das políticas de ações afirmativas como resposta a reivindicação dos movimentos indígenas de Roraima, que almejam qualificar pessoal para atuar nas próprias organizações e atividades nas regiões e comunidades.

\section{Referências bibliográficas}

BRASIL. Ministério da Saúde (MS). Fundação Nacional de Saúde (Funasa). Coordenação Regional de Roraima. Relatório de gestão 2008. [Boa Vista], 2009. Disponível em: < http://www.funasa.gov.br/internet/ 
arquivos/conhecaFunasa/prestContas/RELAT\%C3\%93RIO\%20DE\%20

GEST\%C3\%83O\%20-\%20RR\%20-\%202008.pdf>.

COLLET, Celia Letícia Gouvêa. Interculturalidade e educação escolar indígena: um breve histórico. In: GRUPIONI, Luís Donisete Benzi (Org.). Formação de professores indígenas: repensando trajetórias. Brasília: MEC/Secad, 2006. p. 115-129.

CONSELHO INDÍGENA DE RORAIMA (CIR). Setor de Saúde. Saiba qual a posição do CIR sobre a Saúde Indígena com o fim do contrato com a FUNASA [Projeto de Atenção Básica à Saúde Indígena no Leste de Roraima, período de 2000 a 2008]. 2008. Disponível em: <http://www. cir.org.br/portal/?q=node/644>.

DOMINGUES, Ivan (Org.). Conhecimento e transdisciplinaridade. Belo Horizonte: IEAT/Editora da UFMG, 2001. 72 p.

FLEURI, Reinaldo Matias (Org.). Educação intercultural: mediações necessárias. Rio de Janeiro: DP\&A, 2003.

FREITAS, Marcos Antonio Braga de. Educação escolar indígena: realidade e perspectiva em Roraima. Revista Textos \& Debates, Boa Vista, n. 9, p. 85-112, 2005.

MELATTI, Júlio Cezar. Índios do Brasil. São Paulo: Edusp, 2007.

MORIN, Edgar. Educação e complexidade: os sete saberes e outros ensaios. Organizado por Maria da Conceição Almeida e Edgard Assis de Carvalho. 3. ed. São Paulo: Cortez, 2005.

NICOLESCU, Basarab. Um novo tipo de conhecimento: transdisciplinaridade. In: NICOLESCU, Basarab et al. Educação e transdisciplinaridade. Brasília: Unesco, 2000. p. 9-26.

\section{ORGANIZAÇÃO DOS PROFESSORES INDÍGENAS DE RORAIMA}

(OPIRR). Carta de Canauanim, 4 de maio de 2001. Terra Indígena Canauanim, município de Cantá, Estado de Roraima, 2001.

PROGRAMA de Reestruturação das Universidades Federais de Ensino Superior (Reuni) do Ministério da Educação. Boa Vista, RR: Universidade Federal de Roraima (UFRR), 2007.

PROJETO Político-Pedagógico do Curso de Bacharelado em Gestão Territorial Indígena. Boa Vista, RR: UFRR, Instituto Insikiran, 2009.

POVOS indígenas do Brasil (1996-2000). São Paulo: Instituto

Socioambiental, 2000. 
UNIVERSIDADE FEDERAL DE RORAIMA (UFRR). Conselho de Ensino, Pesquisa e Extensão (Cepe). Resolução no 012/09-CEPE, de 7 de agosto de 2009. Aprova o Projeto Político-Pedagógico do Curso de Bacharelado em Gestão Territorial Indígena. Boa Vista, RR, 2009. Disponível em: $<$ http://ufrr.br/conselhos/index.php?option=com_phocadownload\&view $=$ category\&id $=19: 2009 \&$ Itemid $=5>$.

UNIVERSIDADE FEDERAL DE RORAIMA (UFRR). Conselho de Ensino, Pesquisa e Extensão (Cepe). Resolução no 013/2008-CEPE, de 22 de outubro de 2008. Aprova o Projeto Político Pedagógico do Curso de Licenciatura Intercultural. Disponível em: < http://ufrr.br/conselhos/ index.php?option $=$ com_phocadownload\&view $=$ category\&id $=20: 2008 \&$ Itemid $=5>$.

UNIVERSIDADE FEDERAL DE RORAIMA (UFRR). Conselho Universitário (CUni). Resolução no 011/2009-CUni, de 13 de agosto de 2009. Cria o Curso de Bacharelado em Gestão Territorial Indígena [...]. Disponível em: <http://ufrr.br/conselhos/index.php?option=com_phoca download\&view $=$ category\&id $=41: 2009 \&$ Itemid $=5>$.

UNIVERSIDADE FEDERAL DE RORAIMA (UFRR). Conselho Universitário (CUni). Resolução no 009/2009-CUni, de 2 de setembro de 2009. Dispõe sobre a transformação do Núcleo Insikiran de Formação Superior Indígena em Instituto [...] e aprovação do Regimento Interno [...]. Disponível em: <http://ufrr.br/conselhos/index.php?option=com phocadownload\&view $=$ sections\&Itemid $=5>$.

Marcos Antonio Braga de Freitas, mestre em Sociedade e Cultura na Amazônia pela Universidade Federal do Amazonas (Ufam), é professor do Curso de Licenciatura Intercultural e Coordenador de Extensão do Instituto Insikiran de Formação Superior Indígena da Universidade Federal de Roraima.

mabfreitas@hotmail.com

Recebido em 15 de fevereiro de 2011.

Aprovado em 10 de novembro de 2011. 